\title{
PRAGMATISM AND METAETHICS
}

\author{
Andrew Sepielli \\ University of Toronto
}

Among analytic philosophers, pragmatism tends to elicit two reactions that might seem to stand in tension with one other. The first reaction is confusion about what pragmatism is, exactly. The second is steadfast rejection of it.

It's easier to reconcile these disparate responses when we consider that pragmatism tends to show up under two different guises. The first is as a woolly gestalt, expressed through support for experiment, democracy, fallibilism, and solidarity, and condemnation of authoritarianism, representationalism, Cartesianism, and dogmatic metaphysics. The second is as the simple doctrine that truth is what's good in any way whatsoever to believe. In its first guise, pragmatism tends to provoke confusion; in its second, rejection. As a result, pragmatism occupies at best a precarious position within the mainstream of analytic philosophy. Its influence on contemporary metaethics has been especially weak.

My target reader for this article, then, is someone who is familiar with the basic problemspaces in contemporary metaethics and the moves commonly made within those spaces, but who is not already sympathetic to pragmatism. I want to help such a reader to make sense of pragmatism in some of its many guises, to appreciate both its subtlety and its power as a philosophical stance, and to understand its bearing on some of the main debates within metaethics. 


\section{What Is Pragmatism?}

Let me begin by offering a characterization of pragmatism that will cover as many of those commonly called "pragmatists" as possible without being so capacious as to be useless. First, let us say that to be a pragmatist, one must focus in one's inquiry on normative and evaluative questions concerning thought and its expression. Now, this alone doesn't make one a pragmatist; if it did, then anyone who worked on, say, norms of assertion would count as one. So let us add a second condition: To be a pragmatist, one must take one's theorizing about the norms of thought and expression to obviate the need to vindicate our practices by appeal to at least some of the first-order metaphysical claims that other philosophers think such vindication rests on. Pragmatism, then, is (a) focused on norms and values, and also (b) anti-metaphysical. Furthermore, its anti-metaphysical stance is due to its focus on norms and values; a philosopher whose anti-metaphysical stance is not driven by explicitly normative or evaluative considerations

— for example, a certain sort of logical positivist — is for that reason not a pragmatist.

Now, different pragmatists will couple this focus with different stances towards things like truth, knowledge, rationality, and so on. Some may want to give a positive account of truth in terms of the practical significance of a belief or set of beliefs. Of these, some will go the extra step of saying that claims do not become true until their practical significance is actually manifested. (James 1907; Dewey 1911). Others will offer not so much a theory of truth, but something rather weaker — an elucidation of what happens when you believe something true or something false. (See Misak 2013's discussion of Pierce 1878). Still others will adopt the stance that we can't say anything illuminating in general about truth, and so partly for that reason we should focus instead on on practical utility as an alternative (Rorty 1982: introduction). Others 
might say that we ought to focus on practical consequences in lieu of things like truth, even if we can offer an illuminating account of the latter, since the former are just more worthy of our focus.

A characterization of pragmatism in terms of "focus" may strike you as unsatisfying if you're looking instead for some philosophical thesis that pragmatists, qua "-ists", all believe in. But as a matter of the sociology of ideas, pragmatists are united more by the aforementioned focus, plus their views about its anti-metaphysical significance, than by any philosophical thesis. I would also say that an insistence on theses as opposed to focuses is just the kind of thing that many pragmatists will reject. From my point of view, at least, the difference between a pragmatist who purports to ground truth in practical significance and one who wishes to scrap talk of truth for talk of practical significance is of little, well, practical significance, and as such, does not merit our focus.

Because I've defined pragmatism as a stance according to which the need for first-order metaphysics is obviated, I want to try to introduce the different pragmatisms by considering them as departures, to various extents, from a sort of metaphysically-inflected position that is very common in Anglo-American metaethics. I call this view "archetypal realism", and characterize it in terms of four more specific commitments -- what I label "Correctness", "Domain External/ General", "Subject-Object", and "Structure". Then I will start cutting commitments and see, with each "cut", what views we end up with in philosophy generally, and in metaethics specifically. Additionally, I will try to show how the various sorts of pragmatism provide rationales for dropping the various commitments. 


\section{Pragmatism as a Departure from Archetypal Realism}

Let's start with the archetypical realists's focus. Like everyone, she will see that thought and talk can be good or useful in lots of different ways. A belief can be good in the sense that holding it makes me happy. A spoken sentence can be bad in the sense that it is offensive. But in her role as a philosopher, the archetypical realist's focus on the value of an item will be mainly on whether it is good qua the kind of item it is - e.g. whether a belief is good in the way that beliefs, specifically, can be good. There are different ways of explicating the notion of a belief being good in this way. We might talk about its function or "aim", or about its being supported by (conclusive) object-given, as opposed to state-given, reasons (see Parfit 2001). But it's easiest to understand the object of the archetypical realist's focus as follows: it is on whether a belief is correct, such that a belief's being true is the paradigmatic way of its being correct, and its making its holder happy is not a way of being correct. Call the commitment to this focus Correctness.

The archetypical realist will also think there's some domain-external or at least domaingeneral explanation you can give of a belief's correctness conditions. By "domain-external", I mean that the explanation does not merely advert to facts internal to the domain that the belief is about. So, for example, an explanation of the correctness of the belief that causing pain is wrong that simply went: "Causing pain is wrong", would not be domain-external, nor would an explanation that went: "Causing pain is regarded as wrong by virtuous people". Now, of course, if the belief in question is about the correctness of beliefs or about the things that make them correct, it's going to be difficult for anyone to give a domain-external explanation of their correctness. Any explanation of this sort will be within the domain of the belief. But we can 
nonetheless, perhaps, give a domain-general explanation of such beliefs — "general" in that it explains not only their correctness, but also that of beliefs about giraffes, bosons, numbers, seasons, and swag. Call this commitment Domain-External/General.

The archetypical realist will also have a particular view about the content of these domain-general or domain-external explanations — namely, a view on which the correctness of a belief or a claim is a matter of the relation between things like thought and talk, on the one hand, and the world, more generally, on the other - i.e. a relation of the sort that may obtain between things on the "subject" side of the subject/object divide, and things on the "object" side, like reference or truth-making. This may be contrasted with a view on which what explains the correctness of a belief or claim is a matter of relations that can obtain only between thoughts, utterances, and other broadly "subjecty" things - e.g. the relation of rational commitment. Call this archetypal realist commitment Subject-Object.

Finally, the archetypical realist has a view about the kind of subject-object connection that explains a belief's correctness, and, correspondingly, about what the relata on the "object" side are. Specifically, the view is that a belief is correct on the grounds that the world is structured in a way that corresponds to the syntactic structure of the belief's content (or to the paradigmatic expression of that content). Consider, then, the belief that Barry is tall. Our archetypical realist would explain the correctness of this belief by adverting to an individual, Barry, corresponding to the subject-term "Barry", and Barry's having the property of being tall, corresponding to the predicate "is tall” (see MacBride 2013). (She might further explain Barry's having this property by appealing to his having the property of being 617 " in height, but this latter 
property is not what explains, in the relevant way, the truth of the belief.) Call this last commitment Structure.

If the archetypal realist applies this set of commitments to ethical thought, he arrives at either moral realism (if he believes the world does contain moral properties of the right sort), or else error theory (if he believes it does not).

\section{Cutting "Structure"}

Let us see what a view would look like that kept Correctness, Domain External/

General, and Subject-Object, but cut Structure. Such a view would focus on the correctness of the thought that, say, water is wet, and offer a domain-external or domain-general explanation of that correctness in terms the value or usefulness of that thought, but importantly, without invoking the property of wetness.

The most obvious way of doing that is to offer what, following William James (1907: 512), I'll call an "instrumental" account of truth -- one that explains the correctness of a belief in terms of the values of the thoughts and practices that the belief enables. (Views of broadly this sort appear in James 1907; Dewey 1911; Ramsey 1927; van Fraassen 1980; Whyte 1990; and Blackburn 2005.) Now, it seems to me that some such accounts allow us to avoid metaphysics only in part. I have in mind those views that purport to explain the correctness of a belief by appealing to the truth of other, in some sense more "basic", beliefs or to the veridicality of experiences, which are in turn explained in the archetypical realist manner -- i.e. by finding properties to match predicates, and so on. I'm also thinking of views that appeal, ultimately, to the satisfaction of desires, where this is a matter of the truth of their propositional contents, 
which is explained, again, by finding properties to match predicates, and so on. The first strategy might ground the truth of a belief there's a hole in the bucket by appealing to the truth of beliefs formed on the basis of it -- e.g. that water placed in the bucket will escape. The second strategy might ground the same by appealing to the fulfillment of desires fulfilled by actions done on the basis of the belief; for example, I might choose to put my water in another bucket instead, which will fulfill my desire of not having water escape. In each case, I am purchasing the right to avoid the metaphysics of holes by indulging in the metaphysics of water and escaping (see also Thomasson 2015). (So far, then, pragmatism hasn't delivered on what many take to be its aim -to give us a metaphysical "free lunch".)

Other views, however, may allow us to avoid the metaphysics of properties entirely, through accounts of predictive accuracy and desire-satisfaction that avoid truth, and therefore truthmakers entirely. Jerry Fodor (2007) has argued that we can make sense the idea of a nonconceptual representation being accurate without settling questions of ontology. Because such representations lack logical forms, they can't express predication and quantification, and a representation's ontological commitments are determined by its predicative and quantificational structure (p. 109). (cf. Balog 2009). Consider the difference between pictorial and discursive representation. Suppose first that a book describes Caligula as doing "an evil deed". One can imagine a moral error theorist saying that this description is, strictly speaking, false, since nothing is good or evil. One can also imagine an austere metaphysician who believes there are no such things as actions objecting to the positing of a "deed". That these different theorists disagree shows that discursive representations like a book carry ontological commitments. But now imagine that a painting depicts what I, qua skeptic about neither morals nor actions, would call 
"an evil deed". It seems that all three of the theorists just described could agree that the painting accurately represents reality.

This points the way towards an "instrumental" theory of true belief that avoids properties on the "object" side altogether. We might explain a belief's truth in terms of the non-conceptual representational accuracy of predictions formed on the basis of it; and we might explain the same in terms of the satisfaction of desires, understood in non-conceptual terms as well (see Sepielli 2016). (The latter view allows us to avoid the strange result that the degree to which my desires are satisfied depends upon whether there really are tables, or just particles arranged tablewise, say; or on whether a "vodka martini" really is a martini.)

What does this all have to do with metaethics? Well, we might imagine that, in certain contexts, ethical thoughts could be useful to prediction in just the way that non-ethical ones can be. Recall Nicholas Sturgeon's (1985) famous case involving Selim Woodworth -- the midshipman whose bad character, Sturgeon argued, can help us to explain his lack of success as leader of the Donner Party rescue mission. But what can be a basis for explanation can, in principle, serve as a basis for prediction and control as well. Had they known in 1846 that Woodworth was, in one historian's words, "no damned good", they could have predicted his failure and would have been in a position to avoid it.

You may be skeptical that this really demonstrates the truth of a belief that Woodworth is a bad guy. This belief may be useful in a context where you don't already have beliefs about Woodworth's tendencies, described non-ethically; but if we already have enough of this other information in mind, the additional belief that he's a bad guy seems to afford no more predictive 
or practical value than the belief that he's a good guy. This might make us think that the belief's content is not so much true as it is a fiction that's convenient in some contexts of inquiry and action.

It seems to me that there are two ways for the pragmatist to address this skepticism. One is to tell some story other than the "instrumental truth" one according to which the "good guy" belief, rather than the "bad guy" one, is correct even in this context of inquiry. We'll look at two very different sorts of stories along these lines in the next two sections. The other option is to show how ethical thought and talk can add either predictive or practical power even when the thinker's mind is replete with relevant non-ethical beliefs.

This might be possible if there are representational attitudes to which ethical thoughts bear a special relationship. And indeed, it seems that there may be. For while ethical thoughts and non-ethical ones alike can play a role in prediction, or in guiding action in accordance with our desires, ethical ones seem uniquely positioned to mediate our emotions, and it is at least arguable that emotions themselves are representational. However, most of those who've argued for the representational theory of emotion have held that emotions are representations with conceptual content, and that the concepts contained are ethical (Solomon 1993; Nussbaum 2001). So this doesn't seem like a promising domain-external way of vindicating ethics. But lately some have defended the view that emotions are non-conceptual representations (Gunther 2003; Tappolet 2003). If that is right, then it allows us, perhaps, to say that moral beliefs are true insofar as they form the basis for emotions that accurately represent the world non-conceptually. In doing so, not only would we not have to posit ethical properties -- we wouldn't have to posit any properties. 
To summarize, then, it seems that we might side-step the metaphysics of morality, specifically, by conceiving of the correctness of an ethical judgment "instrumentally" -- either as the basis for a further, correct representation, or else for a successful action. Additionally, we may be able to avoid the metaphysics of truth-making generally, by accounting for the correctness of representations or the satisfaction of desires in terms of a match between their non-conceptual content and the world.

\section{Cutting "Subject-Object"}

Now let's cut the next of the traditional realist's commitments -- Subject-Object. One might think that this can't really be done if we want to maintain Correctness, for how else can we explain the correctness of a belief, ethical or otherwise, except by saying something about how it hooks up with the world? Two ways suggest themselves:

One is that adopted by constitutivist writers like Kant and Habermas. Kant (1785: book III) famously argues that we are rationally committed to accepting the categorical imperative by features that are constitutive of something very basic -- our agency. Habermas (1990) tells us that we are committed to accepting a set of criteria for the correctness of moral norms by virtue of something that is almost as basic, and perhaps more generative of substantive commitments -our participation in moral discourse. It is no part of their arguments that the agent be hooked up correctly with the world.

Habermas, at least, is explicit in labelling his view as "pragmatist", and cites as inspiration for it C.S. Pierce's (1878) gloss on truth as what is settled upon at the end of idealized, social inquiry. But he is equally explicit in denying that that his project of 
"communicative ethics" offers us a theory of ethical truth (1990: 52-7). Especially in his later work, he characterizes truth as requiring some subject-object connection (Habermas 2003; see also Levine 2011). He argues, however, that claims about rightness can nonetheless be "valid" just in virtue of being the ones we'd agree upon in accordance with discourse-constitutive criteria. The ultimate tribunal for a "rightness"-claim are is not the world, generally, that we should understand such a claim as describing; rather, the tribunals are ourselves, albeit ourselves as rational participants in discourse. He writes:

"[M]oral beliefs do not falter against the resistance of an objective world that all participants suppose to be one and the same. Rather, they falter against the irresovability of normative dissensus about opposing parties in a shared social world." (2003: 248)

Another way to drop "subject-object" while maintaining "Correctness" and "Domain External/General" is to embrace something like Robert Brandom's "inferentialist" program. On Brandom's view, we explain when the application of a concept is correct by appealing to the propriety of social, discursive behavior involving that concept -- moves in the "game of giving and asking for reasons" for our commitments. Brandom is not concerned to metaphysically reduce these norms to anything non-normative, or to state the content of the norms in nonnormative vocabulary. He is comfortable, then, with there being "norms all the way down", such that the "sanctions" for fallacies and poorly-supported claims are nothing other than diminutions in deontic status -- "internal" sanctions, as he calls them, rather than "external" ones". Brandom 
is concerned to account for semantic phenomena through a rich explanatory picture, but not to dispel any perceived air of "mystery" involving the normative as such (Brandom 1994a).

So far there's been no sign of the extra-linguistic world on Brandom's picture, and no mention of any constitutive features (of agency, say, or of discourse) that might rationally commit us to certain beliefs. We might wonder, then, how any norm of the aforementioned sort could be correct or incorrect. He brings in the world in two ways. First, he recognizes that what might cause us to make make, support, accept, or reject an assertion is something about the external world. He is not imagining us as floating in an isolation chamber, tossing around assertions. It is just that what makes an assertion correct or incorrect is the network of norms governing discursive behavior, rather than the existence of truth-makers for that assertion. Second, Brandom ingeniously tries to get a subject-object connection "out the back end", as it were: among the many, many things we talk about are representational phenomena like truth, objectivity, representation, and so on. Insofar as he provides an account of what makes assertations correct generally, this applies to assertions about these subject-object notions, from which we can read off facts about when, in fact, a claim is true, or represents the world accurately, and so on (Brandom 1994a; Cf. Price 2011).

Brandom's work has made its way into metaethics through writers like Matthew Chrisman. As Chrisman (2008) conceives of it, inferentialism is an alternative to both realism and expressivism in explaining the meanings of ethical expressions. The realist will want to say that what makes an expression an ethical one is the sort of property it represents objects as having -- namely, an ethical property. The expressivist will want to say that what makes an expression ethical is the kind of mental state it expresses -- namely, a pro-attitude or a plan or 
whatever the story is. The inferentialist rejects the realist's representationalism and the expressivist's "psychologism", holding instead that the meanings of expressions are explanatorily prior to the contents of mental states they express, and that the former are explainable in the manner described above -- by their standing vis a vis a network of norms of public discursive behavior.

Now, Brandom labels his work "pragmatist"; but on what grounds? The idea seems to be this: Brandom's focus is on concept use as a kind of activity, and on the norms governing this activity, and he believes that in so focusing he can skirt metaphysical questions of the sort that seem to confront the moral realist. It is important to be clear on what kind of pragmatism this is, though: First, the inferentialists are focused on only a particular kind of action -- discursive action; and second, they are focused only on a particular kind of value that this action may have -- namely, the kind of value that is proprietary to linguistic action, the kind that inheres in correct or well-supported assertions.

This focus makes sense given the inferentialists' (semantic-theoretic) aims, and indeed, Brandom (1994b) has criticized the aforementioned project of trying to ground correctness of us in the instrumental value of the actions, generally speaking, that a thought produces. But it is open to other pragmatists to have theoretical projects other than semantic ones, and thus to focus on actions more generally, and value more generally.

\section{Cutting "Domain External/General"}

The view that I call "quietism" differs from traditional realism in that not only does it not offer an explanation of how moral thoughts represent the world in terms of moral properties; not 
only does it not offer an explanation in terms of a relationship between the mind and the world; but it does not offer any general explanation in terms of representation, or rationality, of why some ethical views are correct and others aren't. In other words, quietism is what we get when we drop not only "Structure" and "Subject-Object", but also "Domain External/General".

The "neo-pragmatist" Richard Rorty gives voice to metaethical quietism in his rejection of attempts to provide "foundations" for human rights and moral theories generally, on which he offers the following gloss:

"Foundationalist philosophers, such as Plato, Aquinas, and Kant, have hoped to provide independent support for [moral theories]. They would like to infer these...from further premises, premises capable of being known to be true independently of the truth of the moral intuition which have been summarized [by the theories]... To claim such knowledge is to claim to know something which, though not itself a moral intuition, can correct moral intuitions." (1998: 171).

Notably, Rorty doesn't reject the idea that some moral views are better than others; he is not a nihilist. Nor does he accept categorization as a subjectivist or relativist. What he rejects is the project of trying to ground their being better in terms that are not themselves moral. Rorty does so at least partly on the jarringly pragmatic grounds that providing foundations for things like human rights isn't actually a very effective way to make opponents of a human rights regime into supporters. We, the supporters of human rights broadly construed, ought to abandon this project in favor of sentimental education, or, just generally, whatever works. He says that we 
cling to the foundational project for the very same reason he once yearned for the ability to prove to the schoolyard bullies that they should not torment them -- out of a desire for power, to bring about change through domination (in this case in argument), rather than playing on the sentiments of the powerful. (1998: 182; see also Nietzsche 1901: book I).

There is something very appealing, to me at least, about this stance -- of considering the development of domain-external vindications of ethics as just another thing one could do with one's time, and judging it, on practical grounds, not a very good or helpful thing to do. Still, one might worry that unless someone could do this, it can't be the case that some moral claims are correct, or better than others, or anything like that. After all, it seems on the face of it that we can provide these sorts of domain-external vindications of claims within other domains -specifically, I'm thinking, by adverting, to the link between such claims and a believer's ability to predict and/or control the world, but also, perhaps, by providing some other non-trivial account of which cognitive defects those on the wrong side of an ethical debate have exhibited (see Wright 1992). Even if the interest in providing domain-external foundations in ethics can be attributed to power-lust, it nonetheless may be that the existence of such foundations is required for there to be any correct claims in ethics.

There are different ways to answer this question, perhaps the most prominent of which come from metaethicists working in the Wittgensteinian tradition (see, e.g., McDowell 1979; Crary 2009). But let me offer a sketch of an answer along more traditionally pragmatist lines. 
Recall the earlier worry about my initial deployment of the "Woodworth" case: The belief that Woodworth is "no damned good" is predictively and practically useful only in contexts in which the thinker is presumed to believe (or at least, occurrently believe) little about, say, Woodworth's mental makeup and past deeds. But some moral inquiry -- and we might fairly say, particularly fundamental moral inquiry -- takes place against the background of a great many beliefs about the non-moral facts; we are asking about the normative significance of those very facts. In those contexts, we observed, it's not clear that any moral conclusion helps us to predict the world and bring about the general fulfillment of our desires more than any other.

But we might well ask: so what if that's right? What would be a sensible thing to say about moral conclusions reached in these contexts? It seems to me that these instances of moral inquiry are akin to certain non-moral debates that many would label "merely verbal" or "nonsubstantive". James (1907) provides the classic example of the latter: two people agree that a man is chasing a squirrel around a tree and are at odds about whether he is truly going "around the squirrel". In this case, as in the moral one, it does not seem that either answer will help or hurt our overall ability to predict and control the world.

Both in cases of fundamental ethical inquiry an in cases of "non-substantive" nonevaluative inquiry, I am inclined to think that there can be no domain-general or domain-external vindication of any answer as worthy of acceptance. This is because, as a pragmatist, I think that such a vindication would have to account for the links between such answers and predictive/ control value, but in the contexts in which these debates occur, there are no such links (see Stich 1990 on similar themes). No such value is afforded by any answer. In cases like James's "squirrel" debate, though, I am also inclined to say that there will generally be no grounds 
whatsoever for designating either answer as meriting acceptance. I and others will want to say, further, that "it doesn't matter" and "you could go either way".

This is not, however, what I'd want to say about fundamental ethical debates. I would not say of the debate between the sadist and his opponent: "you could go either way". Rather it seems like the resolution of the debate matters; it matters in a way that is specifically moral. These disputes, we might say, are important without being substantive; they're ones in which value is afforded by the outcome, but not predictive/control value -- just plain old moral value. In these debates, then, I'm inclined to say something like this: "Anti-sadism is preferable in that accepting it affords more value than does acceptance of sadism. But its preferability cannot be explained from 'outside' of ethics, for such an explanation would, in my view, have to also explain how a belief in anti-sadism, formed in the relevant context of inquiry, contributes to its holder's ability to predict and control the world. And we've seen that it doesn't." (See Sepielli ms.)

So the pragmatist-quietist will say, expressing his ethical judgment, that sadism is wrong. Pressed as to why, she may express more ethical judgments -- about the badness of pain, about our obligations to others. But if she is asked what makes these judgments the right ones, and is debarred from further expression of ethical judgments, she will say: nothing other than what makes the judgment that the man truly is going "around the squirrel" the right one -- that is to say, nothing.

\section{Cutting "Correctness"}


The most radical view emerges as we drop the last of the archetypal realist's

commitments: Correctness. On this view, our focus in asking about anything -- a belief, a desire, an emotion, a speech act -- should be on its value, generally, or the all-things-considered reasons in its favor. This approach views all things instrumentally; a belief is thought of as just one more tool, alongside and in competition with anything else, that might help us to pursue the good and avoid the bad. This view does not say that we should not ultimately care about a belief's or assertion's correctness at all, although some who hold it might say that. It says only that we oughn't to focus on correctness exclusively, or mostly, or necessarily.

There are two ways we might work ourselves into such a focus, it seems to me -- one more theoretical, the second more practical. The more theoretical one goes like this: "Some philosophers write as though all action is mediated by these re-presentations of the world in our heads. But whether we look at the phenomenology or the physiology, it doesn't seem like it really works that way (unless we twist the notion of representation beyond recognition). Most of the time, we just sort of, well, cope with the world, engaging in little trials and errors, enacting little feedback-and-response cycles that are not mediated by any representation. So philosophy's traditional focus on accurate re-presentations -- e.g. on true belief -- is out of proportion given representation's really quite limited role in human action. And not only is representation less ubiquitous than is commonly thought; it is also less fundamental. The capacity to represent the world can only be fully explained by invoking these other, more 'primitive' capacities. Our theorizing should focus on what's explanatorily more fundamental."

This stance has roots going back at least to Aristotle, and its defenders include Martin Heidegger (1927) and his followers (e.g. Dreyfus 1990; Haugeland 2013; Dreyfus and Taylor 
2015), Dewey (1925; 1929), and the various proponents of anti-representationalist cognitive science and artificial intelligence (Beer 1990; Brooks 1991; van Gelder 1995; Thelen and Smith 1994; Chemero 2011; an excellent philosophical look at this work is Clark 1997).

The more practical path towards a focus on value generally can be put simply: "There is simply no ground for discounting, as theorists, the non-veritistic value that a belief has or helps bring about. After all, it's value, right? Additionally, it is arguable that other sorts of value are more important than the veritistic sort, and even that there is no such thing as veritistic value independent of these other sorts of value -- specifically, of practical and predictive value. So a near-exclusive focus on whether a belief is correct reflects an assignment of values -- deliberate or not -- that is mistaken."

But how, exactly, does dropping "Correctness" make a difference to ethical theorizing? One might think that when we're dealing with beliefs about what's valuable, then surely the most valuable of these beliefs for a person to have will generally be the one that's true.

We are familiar, though, with the distinction between the correctness of a moral theory and the usefulness of that theory as a guide to action. For example, some writers reject utilitarianism as a moral theory on the grounds that it is an inadequate guide to action. Utilitarians typically respond either by arguing that (some sort of) utilitarianism can serve as a good guide to action, or else by denying that a theory's usefulness in directly guiding action is really all that pertinent to its correctness. 
One thing that both sides tend to agree on, if only tacitly, is that the question of a view's correctness is primary -- that what ethics is really, fundamentally about is which theory is right. Usefulness bears on acceptability just insofar as it bears on correctness.

A certain sort of pragmatism is concerned to reject this picture of ethical theorizing. No philosopher has understood and articulated the consequences of this rejection better than Dewey. The following passage from The Quest for Certainty gives compelling expression to his radical re-imagining of ethical inquiry:

"Instead of being rigidly fixed, [moral rules] would be treated as intellectual instruments to be tested and confirmed -- and altered -- through consequences effected by acting upon them. They would lose all pretence of finality...

"The transformation does not imply merely that men are responsible for acting upon what they profess to believe; that is an old doctrine. It goes much further. Any belief...is not just to be acted upon, but is to be framed with reference to its office as a guide to action.... When it is apprehended as a tool and only as a tool, an instrumentality of direction, the same scrupulous attention will go to its formulation as now goes into the making of instruments of precision in technical fields." (1929: 277-8). 
The question that others see as secondary -- "Which cognitive tools would be most effective to solve this problem, here, now (although it may be a temporally extended problem)?" -- is what Dewey regards as paramount.

It seems, nonetheless, that we do often take a stand on which ethical theories are correct. We do this explicitly, as the culmination of ethical inquiry as understood by much of the philosophical tradition; and indeed, it is plausible to think that we must do this implicitly, even in Deweyian inquiry, as part of our assessment of the candidate theories/tools. For even if we manage to get ourselves in the mindset where we stop thinking about a theory's correctness, and start thinking about its value as a tool, don't we judge its value as a tool by the lights of some background theory or disjunction of theories? And don't we thereby implicitly treat these theories as correct?

The Deweyian will regard the explicit inquiry into correctness as mistaken, except on the off-chance that this practice really does furnish $u s$, what with our various limitations, with the best tools for solving practical problems as they arise. Dewey was also concerned, in his later work, to provide debunking genealogies of our concern to settle on a final, correct theory in ethics and in other domains. (See Dewey 1929: chapter 1; also Koopman 2011).

As to the background ethical views to which we appeal in Deweyian inquiry, it is seriously open to question why we should think of agents as implicitly treating these theories as correct. One would need to hear why we should not, instead, think of agents as implicitly treating these theories, too, as useful tools -- tools for assessing tools, or "meta-tools", you might say. But suppose we do say that even the Deweyian inquirer must, at some level, represent theories as correct. It matters, I think, how we theorize about this alleged necessity. We all recognize some 
patterns of thinking as heuristics with respect to the truth -- implementable procedures that tend, over the long term, to maximize the probability of arriving at the truth for beings like ourselves. Similarly, we might think of Dewey as regarding representational activity as a heuristic with respect to value. I think of the Deweyian ideal agent as a kind of super-phronimos who we might imagine as turning to the good without the intermediate, usually costly, step of representing some view of the good as correct, in just the way a sunflower turns to the sun without representing the sun as being here or there. We mere humans, without a sunflowerlike ability to immediately track the good, track it mediately at best. But the Deweyian would say that it is distortive to think of mediating representations as objects of fundamental philosophical concern, rather than simply as a kind of crutch upon which limited beings may occasionally rely.

\section{Related Topics}

Realism and objectivity; the autonomy of ethics; quietism

\section{Acknowledgments}

Thanks to Tristram McPherson, David Plunkett, and James Fritz for their helpful comments on this chapter.

\section{References}

Balog, K. (2009). “Jerry Fodor on Non-Conceptual Content,” Synthese 167(3): 311-20.

Beer, R. (1990). Intelligence as Adaptive Behaviour, Academic Press. 
Blackburn, S. (2005). "Success Semantics”, in H, Lillehammer and D.H. Mellor (eds.), Ramsey's Legacy, Oxford University Press.

Brandom, R. (1994a). Making It Explicit, Harvard University Press.

-(1994b). “Unsuccessful Semantics”, Analysis 54(3): 175-8.

Brooks, R. (1991). “Intelligence without Representation”, Artificial Intelligence 47: 139-59.

Chemero, A. (2011). Radical Embodied Cognitive Science, Bradford Books.

Chrisman, M. (2008). "Expressivism, Inferentialism, and Saving the Debate", Philosophy and Phenomenological Research 77(2): 334-58.

Clark, A. (1997). Being There: Putting Brain, Body, and World Together Again, MIT Press.

Crary, A. (2009). Beyond Moral Judgment, Harvard University Press.

Dewey, J. (1911). "The Problem of Truth", in L. Hickman and T. Alexander (eds.), The Essential Dewey, Volume 2: Ethics, Logic, Psychology, Indiana University Press.

- (1925). Experience and Nature, (1958) Dover Publications.

—- (1929). The Quest for Certainty, (1960) Putnam Publishing Group.

Dreyfus, H. (1990). Being-in-the-World: A Commentary on Heidegger's Being in Time, Division I, Bradford Books.

Dreyfus, H. and C. Taylor (2015). Retrieving Realism, Harvard University Press.

Fodor, J. (2007). "The Revenge of the Given”, in B. McLaughlin and J. Cohen (eds.), Contemporary Debates in the Philosophy of Mind, Blackwell.

van Fraassen (1980). The Scientific Image, Oxford University Press.

van Gelder, T. (1995). "What Might Cognition Be If Not Computation?" Journal of Philosophy 92(7): $345-81$.

Gunther, Y. (2003). "Emotion and Force", in Gunther (ed.), Essays on Nonconceptual Content, MIT Press. 
Habermas, J. (1990). "Discourse Ethics: Notes on a Program of Philosophical Justification", in C. Lenhardt and S.W. Nicholsen (trans.) Moral Consciousness and Communicative Action, MIT Press. - (2003). Truth and Justification, MIT Press.

Haugeland, J. (2013). Dasein Disclosed: John Haugeland's Heidegger, Harvard University Press.

Heidegger, M. (1927). Being and Time, J. MacQuarrie, (trans.) (1962), Harper and Row.

James, W. (1907). Pragmatism, (1995) Dover Publications.

Kant, I. (1785). Groundwork of the Metaphysics of Morals, H.J. Paton (trans.) (2009), Harper Perennial.

Koopman, C. (2011). "Genealogical Pragmatism: How History Matters for Foucault and Dewey", Journal of the History of Philosophy 5(3): 533-61.

Levine, S. (2011). "Truth and Moral Validity: On Habermas' Domesticated Pragmatism", Constellations 18(2): 244-59.

MacBride (2013). "Truthmakers", Stanford Encyclopedia of Philosophy.

McDowell, J. (1979). "Virtue and Reason," The Monist 62(3): 331-50.

Misak, C. (2013). The American Pragmatists, Oxford University Press.

Nietzsche, F. (1901). The Will to Power. W. Kaufman and R.J. Hollingdale (trans). (1968), Vintage.

Nussbaum, M. (2001). Upheavals of Thought: The Intelligence of Emotions, Cambridge University Press.

Parfit, D. (2001). "Rationality and Reasons", in D. Egonsson, J. Josefsson, B. Petersson, and T. Rönnow-Rasmussen (eds.), Exploring Practical Philosophy, Ashgate.

Pierce, C.S. (1878). "How to Make Our Ideas Clear", Popular Science Monthly 12: 286-302.

Price, H. (2011). Naturalism without Mirrors, Oxford University Press.

Ramsey, F.P. (1927). “Truth and Probability”, in Antony Eagle (ed.) (2010) 
Rorty, R. (1982). Consequences of Pragmatism, Cambridge University Press.

-(1998). "Human Rights, Rationality, and Sentimentality", in Truth and Progress:

Philosophical Papers, Cambridge University Press.

Sepielli, A. (2016). "Moral Realism without Moral Metaphysics", in R. Shafer-Landau (ed.) Oxford Studies in Metaethics, Volume XI, Oxford University Press.

Solomon, R. (1993). The Passions: Emotions and the Meaning of Life, 2nd revised edition, Hackett Publishing.

Stich, S. (1990). The Fragmentation of Reason: Preface to a Pragmatic Theory of Cognitive Evaluation, MIT Press.

Sturgeon, N. (1985). "Moral Explanations", in G. Sayre-McCord (ed.) (1988), Essays on Moral Realism, Cornell University Press.

Tappolet, C. (2003). "Emotions and the Intellig. ibility of Akratic Action", in S. Stroud and C. Tappolet (eds.), Weakness of Will and Practical Irrationality, Oxford University Press.

Thelen, E. and L. Smith (1994). A Dynamic Systems Approach to the Development of Cognition and Action, MIT Press.

Thomasson, A. (2015). Ontology Made Easy, Oxford University Press.

Whyte, J.T. (1990). “Success Semantics”, Analysis 50(3): 149-57.

Wright, C. (1992). Truth and Objectivity, Harvard University Press.

\section{Further Reading}

For critical introductions to pragmatism generally, see Misak (2013, cited infra.), as well as R. Bernstein (2010), The Pragmatic Turn, Polity Press; and H.S. Thayer (1973), Meaning and Action: A Critical History of Pragmatism, Bobbs-Merrill. For more on pragmatist meta-ethics, see D. Heney (2016), Toward A Pragmatist Metaethics, Routledge; S. Pihlstrom (2005), Pragmatic Moral Realism: A Defence, Rodopi; and C. Misak (2000), Truth, Politics, and Morality, Routledge. For reading on pragmatism and ethics more broadly, see S. Fesmire (2003), John Dewey and Moral Imagination: Pragmatism in Ethics, Indiana University Press; T. Lekan (2003), Making Morality: Pragmatist Reconstruction in Ethical Theory, Vanderbilt University Press; and J. Welchman (1997), Dewey's Ethical Thought, Cornell University Press. Finally, I recommend to anyone with an interest in moral psychology G.H. Mead, Mind, Self, and Society, C. Morris (ed.), University of Chicago Press. 


\section{Biographical Note}

Andrew Sepielli is an assistant professor of philosophy at the University of Toronto. He works on meta-ethics and normative ethics, and is currently writing a book on pragmatism and moral objectivity. 